\title{
Frequency of satisfaction and dissatisfaction with practice among rural-based, group-employed physicians and non-physician practitioners
}

\author{
Anthony C. Waddimba ${ }^{1,2^{*}}$, Melissa Scribani ${ }^{1}$, Nicole Krupa ${ }^{1}$, John J. May ${ }^{1,3}$ and Paul Jenkins ${ }^{1}$
}

\begin{abstract}
Background: Widespread dissatisfaction among United States (U.S.) clinicians could endanger ongoing reforms. Practitioners in rural/underserved areas withstand stressors that are unique to or accentuated in those settings. Medical professionals employed by integrating delivery systems are often distressed by the cacophony of organizational change(s) that such consolidation portends. We investigated the factors associated with dis/ satisfaction with rural practice among doctors/non-physician practitioners employed by an integrated healthcare delivery network serving 9 counties of upstate New York, during a time of organizational transition.

Methods: We linked administrative data about practice units with cross-sectional data from a self-administered multi-dimensional questionnaire that contained practitioner demographics plus valid scales assessing autonomy/ relatedness needs, risk aversion, tolerance for uncertainty/ambiguity, meaningfulness of patient care, and workload. We targeted medical professionals on the institutional payroll for inclusion. We excluded those who retired, resigned or were fired during the study launch, plus members of the advisory board and research team. Fixedeffects beta regressions were performed to test univariate associations between each factor and the percent of time a provider was dis/satisfied. Factors that manifested significant fixed effects were entered into multivariate, inflated beta regression models of the proportion of time that practitioners were dis/satisfied, incorporating clustering by practice unit as a random effect.
\end{abstract}

Results: Of the 473 eligible participants. 308 (65.1\%) completed the questionnaire. $59.1 \%$ of respondents were doctoral-level; $40.9 \%$ mid-level practitioners. Practitioners with heavier workloads and/or greater uncertainty intolerance were less likely to enjoy top-quintile satisfaction; those deriving greater meaning from practice were more likely. Higher meaningfulness and gratified relational needs increased one's likelihood of being in the lowest quintile of dissatisfaction; heavier workload and greater intolerance of uncertainty reduced that likelihood. Practitioner demographics and most practice unit characteristics did not manifest any independent effect. (Continued on next page)

\footnotetext{
*Correspondence: waddimba@gmail.com

1 Bassett Healthcare Network, Research Institute, 1 Atwell Road, Cooperstown, NY 13326, USA

${ }^{2}$ Columbia University College of Physicians and Surgeons, 630 West 168th St,

New York, NY 10032, USA

Full list of author information is available at the end of the article
} 
(Continued from previous page)

Conclusions: Mutable factors, such as workload, work meaningfulness, relational needs, uncertainty/ambiguity tolerance, and risk-taking attitudes displayed the strongest association with practitioner satisfaction/dissatisfaction, independent of demographics and practice unit characteristics. Organizational efforts should be dedicated to a redesign of group-employment models, including more equitable division of clinical labor, building supportive peer networks, and uncertainty/risk tolerance coaching, to improve the quality of work life among rural practitioners.

Keywords: Job satisfaction, Quality of work life, Rural healthcare, Health workforce, Physicians, Nurse practitioners, Physician assistants, Inflated beta regression

\section{Background}

The widespread dissatisfaction among United States (U.S.) clinicians could endanger the success of ongoing systemic reforms [1]. Rapid change in the healthcare landscape is exerting enormous psychological pressure on practitioners by escalating regulatory/documentation requirements, increasing risk of malpractice litigation, imposing value-based purchasing or accountable-care standards, and eroding clinical autonomy [2-6]. The new focus on patient-centered medicine has often relegated practitioner well-being to the back seat [7]. Yet numerous reports highlight the increasing discontent, distress, frustration, and burnout among medical professionals [8-11]. U.S. physicians are more prone to burnout [12], and more likely to engage in suicide ideation or to die from work-related suicide than other working adults [13, 14]. It sometimes seems questionable who are the more distressed group, practitioners or patients [15]. Practitioner dissatisfaction is linked to patient dissatisfaction [16], inferior prescribing [17], suboptimal care [18], and surgery errors [19]. It foments professional withdrawal behaviors such as change of specialty, change of organization, unwillingness to mentor trainees, not recommending a medical career, and/or leaving medicine $[20,21]$, which threaten long-term stability of the clinician workforce. Loss of a practitioner disrupts continuity of care for patients and forces other practitioners to take on a higher workload in the interim [22]. The total cost of replacing a departing fulltime physician ranges from several hundred thousand to over one million dollars [23, 24], making practitioner dissatisfaction very expensive for healthcare organizations.

Rural practitioners, unlike their urban counterparts, face unique challenges such as lengthy distances between service access points, geographical or cultural isolation, resource-poor under-insured and underserved patient populations, and lower rates of reimbursement/remuneration [25-27]. Dual relationships such as having a patient who doubles as a neighbor or friend or minister, are common in close-knit rural communities [28]. The work life of rural-based practitioners thus includes the additional stressor of balancing hard-to-navigate private and professional boundaries [29-31]. Yet practitioners of a certain disposition [32] might prefer such familiarity and community bonds $[33,34]$ to the anonymity of urban practice. Data on work-related wellbeing among rural practitioners, during the contemporary wave of systemic and institutional reforms, is still quite fragmented [35].

Given the competition in the current healthcare marketplace, many hospitals are merging with physician groups to form accountable-care organizations (ACOs) and most hitherto autonomous solo or group practices will likely face mergers or outright purchase by larger hospitals, resulting in more integrated delivery systems [36, 37]. Organizational restructuring in an integrating and consolidating healthcare delivery system can be seen by medical practitioners as a threat to their professional identity and workplace wellbeing [38]. An increasing proportion of medical professionals will become salaried employees in these integrating systems [39]. Practitioners who work as group-model employees face further constraints on their clinical autonomy and caps on their earning potential. Some reports suggest that employed practitioners are more dissatisfied than their independent counterparts [40]. In one study, hospitalemployed family practitioners were less satisfied with being a physician than independent counterparts, and were more likely to leave practice [41]. Further research on the factors that exert the strongest influence on job dis/ satisfaction among medical practitioners who are employed in integrated systems can inform efforts that seek to optimize wellbeing by balancing institutional goals with practitioners' professional needs during and after consolidation [42].

Studies of job satisfaction among rural practitioners are often limited to one section of the workforce, e.g. physicians [43], physician assistants [44], or nurse practitioners [45]. Yet medical professionals from diverse disciplines increasingly work together on the same team [46]. We triangulated information from self-administered surveys with administrative data at the service unit level in a study whose objective was to investigate factors associated with the frequency of satisfaction and dissatisfaction with practice among physician, pharmacist, nurse practitioner, and physician assistant employees of a healthcare network serving nine rural counties of upstate New York. We 
aimed to compare factors that predict satisfaction but not dissatisfaction, dissatisfaction but not satisfaction, or both satisfaction and dissatisfaction. Unlike prior studies, we utilized a measure of affective job satisfaction based on fluctuation in the valence of job-related affect, and assessing the frequency of feeling satisfied or dissatisfied. Our purpose was to inform efforts at minimizing practitioner distress during changes to more integrated delivery systems in underserved/rural settings.

\section{Conceptual model}

Job satisfaction was defined in this study as "a pleasurable or positive emotional state resulting from the appraisal of one's job or job experiences" [47]. We focused on global job satisfaction, i.e. overall feelings about one's practice as a whole, and not on facet satisfaction, i.e. feelings about specific aspects of one's practice [48]. This definition highlights the affective component of job satisfaction [49]. Streams of workplace events do generate positive or negative emotional reactions and mood changes among individuals [50], which influence their happiness at work. Affective reactions, unlike personal traits, tend to fluctuate from day to day and setting to setting $[49,51]$. In our conceptualization, the frequency (more than the intensity) of a practitioner's happiness or unhappiness [52] with their practice determines their overall satisfaction or dissatisfaction.

The Motivation-Hygiene theory posits that some factors (motivators) influence job satisfaction but not dissatisfaction, and others (hygiene factors) cause dissatisfaction when absent/inadequate but hardly affect satisfaction [53]. We investigated factors that are motivators (affect satisfaction, not dissatisfaction), hygiene factors (predict dissatisfaction alone), and both (predict satisfaction and dissatisfaction). We further treated job dis/satisfaction as a function of the degree to which a practitioner's professional needs are fulfilled or unfulfilled by their practice, i.e. concordance between a practitioner's needs and the need-gratifying capacity of their clinical work [54]. Self-determination Theory (SDT) posits that goal-directed behavior is motivated by the drive to satisfy three universal innate needs: autonomy, relatedness, and competence [55]. We focus, in this study, on personal needs for autonomy and relatedness as predictors of job satisfaction. We incorporate additional dimensions that link workplace well-being to: perceived meaningfulness of work $[56,57]$, risk aversion [58] (e.g. due to fear of malpractice lawsuits [5]), intolerance of ambiguity or uncertainty [59], work load [60], and job demands [61]. We finally include contextual factors such as practitioners' personal attributes and work environment characteristics in our conceptual model. See Fig. 1 for an illustration of this model.

\section{Methods}

\section{Study design}

This study analyzes cross-sectional observational data generated as part of the Practitioner Resilience, Adaptability and Well-Being Study, a longitudinal research project investigating a community of practitioners serving in central New York $[62,63]$.

\section{Study setting and context}

The study was conducted within the context of a rural integrated health services delivery system with a catchment population dispersed over a nine-county region of central New York covering 5,600 square miles. This network comprises a 180-bed Columbia University-affiliated academic medical center, six community hospitals, 31 outreach clinics/primary practices, a long term care facility and 20 school-based health centers. It has enjoyed a majority share of the market for health services provision to large portions of this catchment population, with scarce competition from other payers, since the 1930's. The network receives approximately 700,000 ambulatory care visits annually.

The medical staff each entered an individual contract with the organization to be part of a multispecialty group-employed practice under a capitated reimbursement model. The study occurred against the backdrop of significant organizational changes such as the rolling out of a network-wide EPIC $C^{\mathrm{mx}}$-based electronic medical record, impending retirement of the long-time central executive officer, management pressure on clinicians to increase the volume of patients seen, and budget deficitreduction measures such as a hiring freeze on nonessential staff. This was in addition to changes in clinical practice resulting from the escalating state and federal mandates attached to health system reforms, and preexisting stressors inherent in the institution's isolated, rural setting.

\section{Sampling and data collection Sample selection}

In order to be considered for inclusion in the study, an individual had to be a salaried clinical staff member on the institutional payroll. We excluded temporary staff on locum tenens from the study owing to their lack of binding ties to the institution. We further excluded residents/trainees. Among prospective recruits $(N=493), 5$ resigned or were terminated during the final planning and promotion phase of the study, 3 left clinical practice altogether, and 12 served on the study team or its advisory board and were excluded, leaving a study sample of 473 clinicians. 


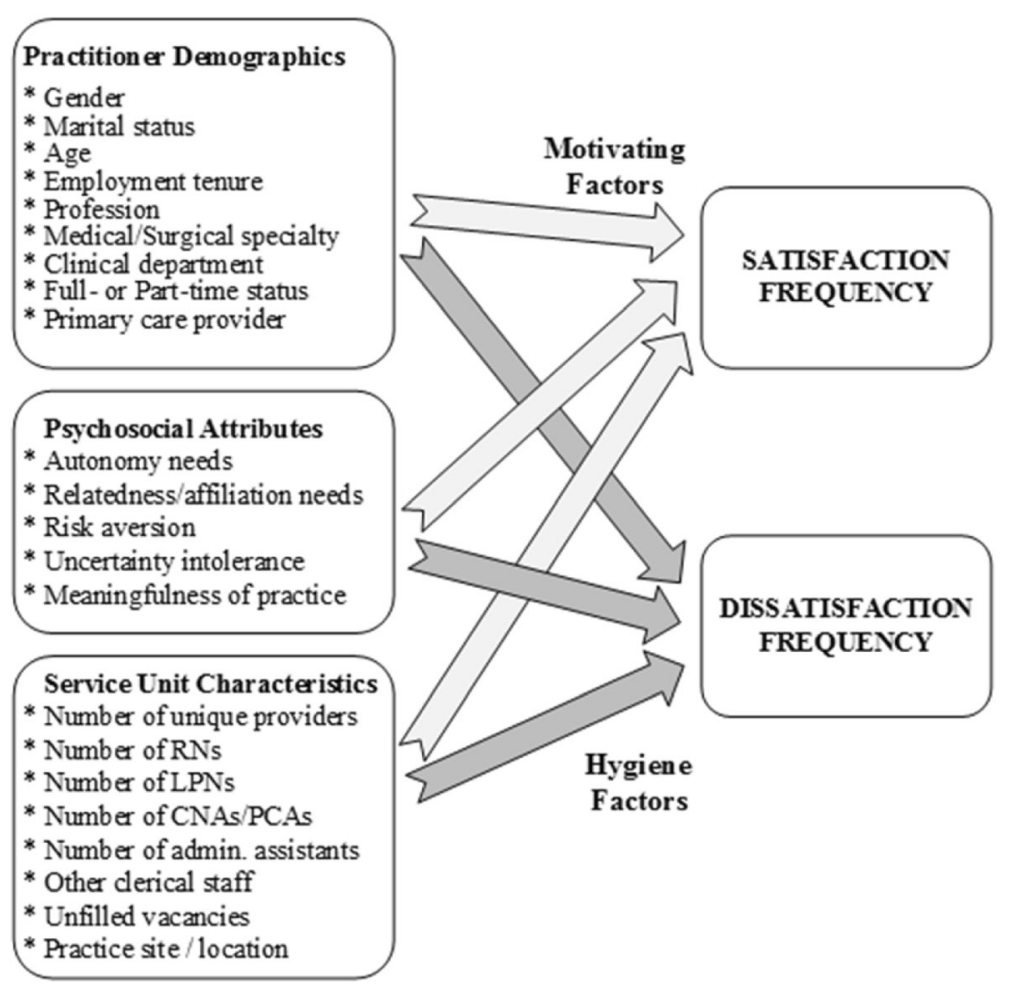

Fig. 1 Conceptual model of satisfaction and dissatisfaction with practice among rural practitioners

\section{Survey/Questionnaire}

The main data collection instrument was a 5-page selfadministered questionnaire that combined demographic information and pre-validated, reliable scales measuring psychological needs, risk profile, meaningfulness, burnout, resilience, and job satisfaction (measures described below). The questionnaire was tested and piloted among members of the Advisory Board and Internal Medicine residents. The final version took an average of 15-20 min to complete. Its distribution was preceded by wide publicity at Medical Staff and department meetings with the help of opinion leaders and local champions. The rollout strategy followed standard procedures in the literature $[64,65]$. A letter announcing the survey was e-mailed by the Research Institute Director to the Medical Staff listserv, followed 5 days later by an e-mail from the Advisory Board. Questionnaires were distributed both as a SurveyMonkey ${ }^{\odot}$ hyperlink by e-mail and a hard-copy form via the network's inter-office mailing system. Reminders were e-mailed to nonresponders at two and four weeks from the start date. Those still unresponsive after six weeks received a repeat solicitation with the e-mail hyperlink and hard-copy questionnaire. Aided by local champions, we conducted further publicity at various division/departmental meetings with a final round of surveys sent electronically and by hardcopy to nonresponders at the 12 -week point.

\section{Administrative data}

Supplementary information, at the aggregate level of the service unit and clinical department, was obtained from the institution and merged with the survey data.

\section{Measures and variables}

Principal Outcome(s): Self-reported satisfaction with practice was the main outcome for this study. This was captured by a single questionnaire item that asked respondents to estimate a percentage of time that they were satisfied and a percentage of time that they were not satisfied with practice. The item is an adaptation of the positive affect frequency estimates in the Fordyce Emotions Questionnaire [66], which is under-utilized even though its internal consistency reliability compares favorably with other measures of subjective well-being $[51,67]$. This Fordyce item has been used to assess happiness with work in other studies [68] but we found no reports in the literature of its adaptation to job satisfaction among medical practitioners. Global job satisfaction is conceptually unidimensional and is reliably captured by a single questionnaire item [69].

Needs: We utilized the autonomy and relatedness subscales of the Basic Psychological Needs at Work Scale [70] to assess gratification of needs for autonomy and relatedness. The autonomy subscale comprises four items (e.g. "I can use my judgment when solving work-related 
problems") and the relatedness subscale consists of four items (e.g. "When I'm with the people from my work environment, I feel understood"). All items are positively worded and use a six-point Likert-style response format ranging from 1 (strongly disagree) to 6 (strongly agree). Each subscale is scored by deriving the mean of its constituent items.

Work Meaningfulness: was assessed by the Personal Meaning in Patient Care scale [71], in which respondents rate the extent to which they derive "a sense of personal meaning" in their work with patients. The scale comprises six items (e.g. "Feeling deep connections with my patients"), each with a four-point Likert-style response format ranging from 1 (not at all) to 4 (a great deal), and is scored by summing up all the items.

Risk aversion: was captured by two items from the sixitem Risk-Taking Scale [58] of the Jackson Personality Inventory [72]. The two items selected were "I try to avoid situations that have uncertain outcomes" and "I rarely, if ever, take risks when there is another alternative". Responses are on a four-point Likert-style scale ranging from 1 (strongly agree) to 4 (strongly disagree). They were reverse-coded and summated so that higher scores would indicate greater aversion to risk.

Tolerance of uncertainty/ambiguity: was assessed by two items from the 13-item Stress from Uncertainty subscale of the Physicians' Reactions to Uncertainty in Patient Care Scale [59]. The items selected were: "The uncertainty of patient care often troubles me" and "I usually feel anxious when I'm not sure of a diagnosis". We formatted responses on a four-point Likert-style scale ranging from 1 (strongly agree) to 4 (strongly disagree), which we reverse-coded and summed so that higher scores would indicate greater discomfort with uncertainty.

Work load: was captured by the perceived workload scale, developed specifically for the parent project and described in a previous report [62]. It consists of five items (e.g. "I feel stressed out from caring for too many patients"), each scored according to a four-point Likertstyle frequency rating ranging from 1 ("Never $[0 \%$ of the time]") to 4 ("Frequently [ $>75 \%$ of the time]"). The "perceived workload" score is derived by summing up the five items, with a higher score indicating a heavier workload.

Practitioner demographics: included gender, marital status, fulltime status, age (years), profession, medical specialty, clinical department, scope of practice, direct patient care versus ancillary care, primary versus specialty/subspecialty care, and employment tenure with the organization (in years).

Practice unit characteristics: that were examined included geographic location, total number of practitioners on the unit, both total and per-practitioner numbers of administrative managers, nursing staff, other support staff, as well as unfilled vacancies or open positions.

\section{Statistical analysis}

Both of the dependent variables were percentages. $25 \%$ of values were between $80-100 \%$ for percent of time satisfied and $50 \%$ of values lay between 0 and $20 \%$ for percent of time dissatisfied (see Fig. 1). Our analytic strategy investigated factors that predicted the likelihood of belonging to the top quintile in satisfaction (satisfied $80-100 \%$ of the time) separately from being satisfied < $80 \%$ of the time; and that of being within the bottom quintile in dissatisfaction (dissatisfied $0-20 \%$ of the time) separately from being dissatisfied $>20 \%$ of the time. For the purposes of statistical modeling, we reformatted the outcomes as proportions (with bounded values between 0 and 1 ). We then modeled the outcomes via a maximum likelihood generalized additive model for location, scale and shape (GAMLSS) with an inflated beta distribution. Beta distributions can take a wide variety of shapes and do not require the symmetry assumption necessary for ordinary least squares regression, so they are more flexible in modeling outcomes that are formatted as rates, proportions or percentages [73-77]. We thus assumed a beta distribution, rather than a normal distribution, for values of proportion of time satisfied that were less than 0.8 and of proportion of time dissatisfied that were above 0.2 , with probability mass parameters for satisfaction frequencies of $0.8-1.0$ and dissatisfaction frequencies between $0.0-0.2$. In $\chi_{0}$-inflated models ( $\chi_{0}$ being a value between 0 and 1 ), where the distribution of the inflation presents $\geq 2$ credible partitions, modeling a wider interval (e.g. $0-0.2$ or $0.8-1$ ), rather than a probability anchored on a single value (e.g. 0 or 1), is justified [78]. The variance is not treated as a nuisance parameter [79] in an inflated beta regression model, but is explicitly modeled concurrently with the mean and inflation. Three generalized linear sub-models were fit using maximum likelihood estimation. The three functions modeled: (a) the mean of the beta distribution with a logit link (mean or location submodel); (b) the variance of the beta distribution with a log link (variance submodel); and (c) the probability mass parameter with a logit link (inflation submodel). ${ }^{1}$ An inflated beta regression fits three submodels because some factors can influence the mean without affecting variance or inflation parameters; or influence the variance with no effect on the mean or inflation; or influence the inflation but neither the mean nor variance. We tested associations between each explanatory variable and changes in the mean, variance, and inflation of the outcome(s) simultaneously. These univariate inflated beta regression models, whose purpose was variable selection, only included fixed effects. We used the standard criterion 
of $p<0.05$ to determine significant mean, variance, and inflation regressors during the variable selection process.

Covariates that were significant in univariate mean, variance, or inflation sub-models were entered into an multivariable inflated beta regression $[80,81]$ model that incorporated the multivariate mean, variance and inflation associations as fixed effects and clustering by service unit as a random effect. Multivariable models were refined by dropping the mean, variance or inflation regressors that did not meet the significance threshold $(p<$ $0.05)$. Variables were further assessed for removal by comparing goodness of fit, based on the Akaike Information Criterion (AIC) and Bayesian Information Criterion (BIC), between models with and without the variable. We synthesized final, parsimonious models incorporating only variables that manifested a significant multivariate association with change in the mean, variance, or inflation of the outcomes(s), after adjusting for other covariates and for clustering. All analyses were performed via Statistical Analysis Software (SAS) version 9.3 from SAS Inc. (Cary, NC). The NLMIXED procedure was used to implement univariate and multivariable zero- and one-inflated beta regression models. We excluded one extreme outlier for percent of time satisfied (0 \%) from models for that outcome.

\section{Results}

308 (65.1\%) of the 473 survey recipients returned completed questionnaires. Respondents were $53.9 \%$ male, $80.5 \%$ married, $81.9 \%$ fulltime employees, $59.1 \%$ with doctoral degrees and $40.9 \%$ advanced-practice clinicians. Their mean (95\% confidence interval) age and organizational tenure $(95 \% \mathrm{CI})$ were $49.2(47.9,50.6)$ and $10.3(9.3,11.3)$ years, respectively. $97.7 \%$ of the respondents $(n=301)$ reported satisfaction ratings, and $97.4 \%(n=300)$ provided dissatisfaction ratings. The median (q1, q3) percent of time that practitioners were satisfied with their clinical practice was $60(30,80) \%$. They reported being dissatisfied at a median (q1, q3) frequency of $20(10,30) \% .30 .6 \%$ of the study sample were in the top quintile of satisfaction (satisfied $\geq 80 \%$ of the time), whereas $54.7 \%$ were in the bottom quintile in dissatisfaction (dissatisfied $\leq 20 \%$ of the time). Figure 2 illustrates the distribution of professional satisfaction and dissatisfaction among the survey respondents. Table 1 depicts the characteristics of survey respondents.

Table 2 outlines the results of the univariate fixedeffects beta regressions of the job satisfaction outcome on each explanatory variable. These variables had a significant, univariate association with changes in the mean of the beta distribution for the proportion of time that practitioners were satisfied: gender (male versus female), marital status (married versus unmarried), length of organizational tenure ( $\geq 15$ versus $<15$ years), fulltime (fulltime versus part-time or per diem) status, working in primary healthcare, perceived workload, autonomy needs, relational needs, and the perceived meaningfulness of practice. Those with a significant, unadjusted association with changes in the variance of the beta distribution for the frequency of satisfaction with practice were: gender, marital status, tenure, fulltime status, profession (doctor versus APC), and primary care specialty. A significant, unadjusted association with the likelihood of a practitioner feeling satisfied $80-100 \%$ of the time was found with: being married, age group $(<45$ versus $\geq 45$ years), working fulltime, being an APC, working outside of primary care, perceived workload, autonomy needs, relational needs, work meaningfulness, tolerance of ambiguity and the levels of support staff on a unit.

Table 3 outlines the results of the univariate fixedeffects beta regressions of the dissatisfaction outcome on each covariate. These covariates had a significant, univariate association with the mean for the proportion of time that practitioners were dissatisfied: gender, marital status, fulltime status, being an APC, working in primary care, workload, autonomy needs, relational needs, and the size of a clinical unit. The significant variance regressors, in unadjusted models, were: gender, marital status, age group, fulltime status, profession, working in primary care or not, autonomy, risk aversion, and the size of a clinical unit. Significant regressors in unadjusted fixed-effects zero-inflation beta regression models were: gender, being married, age group, tenure category, fulltime status, being an APC, not working in primary care, workload, autonomy, relatedness, meaningfulness, risk aversion and tolerance of uncertainty.

In the parsimonious mixed-effects one-inflated multivariable beta regression model of satisfaction frequency (Table 4a), the independently significant mean regressors were workload, relational needs, and meaningfulness; none of the covariates was an independently significant variance regressor; but significant, unadjusted associations with the zero-inflation were manifested by workload, meaningfulness, intolerance of uncertainty, and support staff FTEs on the clinical unit. The interpretation of the mean parameters is that, on average, a heavier workload was associated with decreased likelihood of being frequently satisfied, whereas higher gratification of autonomy and relatedness needs plus finding greater meaning in work were linked to increased frequency of satisfaction. The interpretation of results for the one-inflation submodel is that a heavier workload and greater intolerance for uncertainty are associated with decreased likelihood of being a highly satisfied practitioner, whereas finding greater meaning in patient care increases that likelihood. 


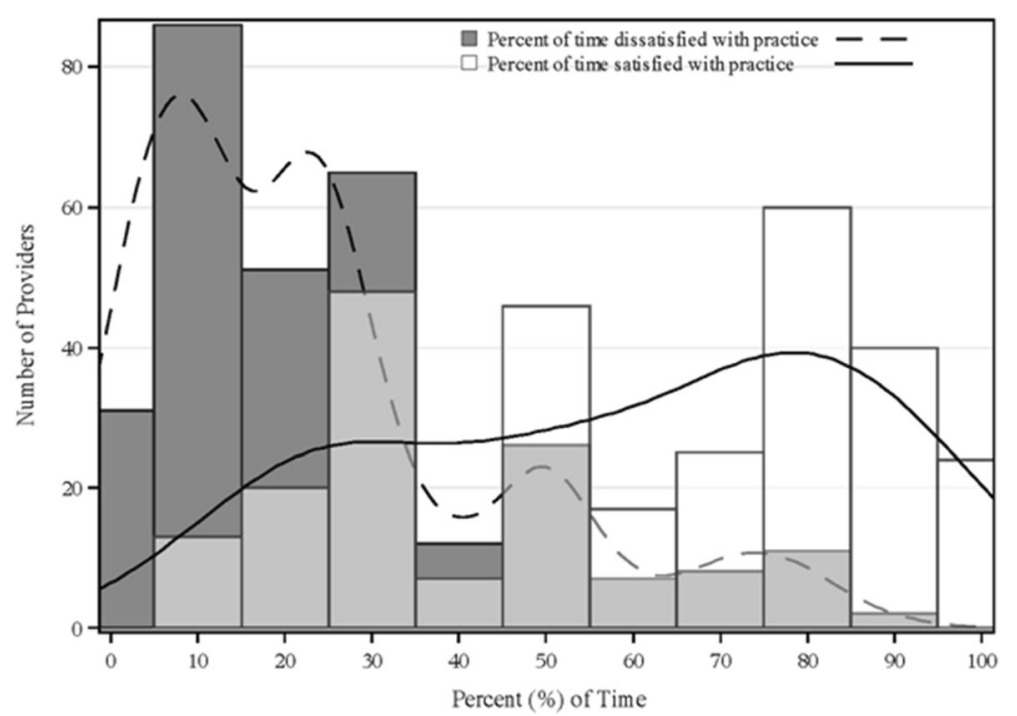

Fig. 2 Distribution of satisfaction and dissatisfaction frequency among practitioners

Table 1 Characteristics of the survey respondents by satisfaction and dissatisfaction frequency

\begin{tabular}{|c|c|c|c|}
\hline \multirow[t]{2}{*}{ Variable } & $\begin{array}{l}\text { Total sample, } \\
N=308\end{array}$ & \multirow{2}{*}{$\begin{array}{l}\text { Satisfied } \geq 80 \% \\
\text { of the Time, } N=92 \\
N(\%)\end{array}$} & \multirow{2}{*}{$\begin{array}{l}\text { Dissatisfied } \leq 20 \% \\
\text { of the Time, } N=164 \\
N(\%)\end{array}$} \\
\hline & $N(\%)$ & & \\
\hline Male Gender & $166(53.9)$ & $52(56.5)$ & $90(54.9)$ \\
\hline Married & $248(80.5)$ & $80(87.0)$ & $141(86.0)$ \\
\hline Age $<45$ years & $117(38.4)$ & $36(40.0)$ & $64(39.8)$ \\
\hline Organizational Tenure $<15$ years & $228(74.0)$ & $69(75.0)$ & $119(72.6)$ \\
\hline Works Full Time & $252(81.8)$ & $78(84.8)$ & $134(81.7)$ \\
\hline Works Part Time or Per Diem & $56(18.2)$ & $14(15.2)$ & $30(18.3)$ \\
\hline Advanced-Practice Clinician/Non-Physician & $126(40.9)$ & $40(43.5)$ & $73(44.5)$ \\
\hline Doctor & $182(59.1)$ & $52(56.5)$ & $91(55.5)$ \\
\hline Primary Care Practitioner & $99(32.1)$ & $21(22.8)$ & $43(26.2)$ \\
\hline Non-Primary Care Practitioner & $209(67.9)$ & $71(77.2)$ & $121(73.8)$ \\
\hline \multirow[t]{2}{*}{ Small Clinical Unit (Number of Practitioners $\leq 5$ ) } & $92(30.7)$ & $25(28.4)$ & $43(27.4)$ \\
\hline & Median $\left(\mathrm{Q}_{1}, \mathrm{Q}_{3}\right)$ & Median $\left(\mathrm{Q}_{1}, \mathrm{Q}_{3}\right)$ & Median $\left(\mathrm{Q}_{1}, \mathrm{Q}_{3}\right)$ \\
\hline Number of Support Staff Full-time Equivalents (FTEs) & $5.1(2,9)$ & $4(2,7.6)$ & $4(2,7.6)$ \\
\hline Perceived Workload & $12(10,14)$ & $9(8,12)$ & $10(8,12)$ \\
\hline Autonomy Needs & $5.3(4.8,5.8)$ & $5.8(5,6)$ & $5.5(5,6)$ \\
\hline Relatedness Needs & $5.0(4.3,5.3)$ & $5(4.5,5.8)$ & $5(4.8,5.5)$ \\
\hline Meaningfulness of Practice & $3.3(2.8,3.7)$ & $3.5(3,3,9)$ & $3.4(3.0,3,8)$ \\
\hline Risk Aversion & $5(4,6)$ & $5(4,6)$ & $5(4,6)$ \\
\hline Intolerance of Uncertainty/Ambiguity & $5(4,6)$ & $6(4,6)$ & $5(4,6)$ \\
\hline Percent of Time Satisfied & $60(30,80)$ & $90(80,95)$ & $80(70,90)$ \\
\hline Percent of Time Dissatisfied & $20(10,30)$ & $5(2,10)$ & $10(5,15)$ \\
\hline
\end{tabular}


Table 2 Univariate beta regressions ${ }^{a}$ of the proportion of time that practitioners were satisfied

\begin{tabular}{|c|c|c|c|}
\hline \multirow[t]{2}{*}{ Parameter } & Mean sub-model & \multirow{2}{*}{$\begin{array}{l}\text { Variance sub-model } \\
\text { Estimate (standard error) }\end{array}$} & \multirow{2}{*}{$\begin{array}{l}\text { One-inflation sub-mode } \\
\text { Estimate (standard error }\end{array}$} \\
\hline & Estimate (standard error) & & \\
\hline Male gender & $0.3810(.0573)$ & $0.8669(.0936)$ & $0.1495(.1287)$ \\
\hline Married & $0.4103(.0601)$ & $0.8296(.0930)$ & $0.3584(.1412)$ \\
\hline Age $<45$ years & $-0.3709(.3607)$ & $-0.9584(.9811)$ & $-1.8971(.8408)$ \\
\hline Organizational Tenure $<15$ years & $0.3775(.0605)$ & $0.9332(.0911)$ & $0.2006(.1274)$ \\
\hline Works Fulltime & $0.2949(.0628)$ & $0.8542(.0956)$ & $0.2996(.1380)$ \\
\hline Works Part-time/Per Diem & $0.5157(.0793)$ & $0.9182(.1410)$ & $0.0170(.2120)$ \\
\hline Doctor & $0.0014(.0626)$ & $0.3838(.1005)$ & $-0.2160(.1368)$ \\
\hline Advanced-Practice Clinician (APC) & $-0.0815(.0565)$ & $0.4197(.0899)$ & $-0.4034(.1262)$ \\
\hline Works in Primary Care & $0.3846(.0624)$ & $0.8888(.1061)$ & $-0.3182(.1715)$ \\
\hline Not in Primary Care & $0.3470(.0566)$ & $0.8457(.0900)$ & $0.3478(.1280)$ \\
\hline Workload $\psi$ & $-0.3111(.0616)$ & $-0.1526(.1183)$ & $-1.1312(.1769)$ \\
\hline Autonomy Needs $\psi$ & $0.2996(.0599)$ & $-0.0582(.0995)$ & $0.3714(.1543)$ \\
\hline Relatedness Needs $\psi$ & $0.3417(.0609)$ & $-0.0958(.1131)$ & $0.3697(.1474)$ \\
\hline Meaningfulness of Practice $\psi$ & $0.1877(.0550)$ & $-0.0458(.0885)$ & $0.4522(.1455)$ \\
\hline Risk Aversion $\psi$ & $-0.0309(.0548)$ & $0.1397(.0911)$ & $-0.1849(.1274)$ \\
\hline Intolerance of Uncertainty $\psi$ & $-0.0805(.0608)$ & $0.0745(.1000)$ & $-0.4309(.1307)$ \\
\hline Unit Support Staff F.T.E.S $\psi$ & $0.0571(.0473)$ & $0.0755(.0800)$ & $-0.4239(.1625)$ \\
\hline Clinical Unit of $\leq 5$ Practitioners & $-0.3398(.5085)$ & $0.3983(.6372)$ & $-0.9243(.7456)$ \\
\hline
\end{tabular}

Note: Bolded figures indicate statistical significance at the alpha $=0.05$ significance level

$\Psi=$ This continuous variable was standardized

${ }^{a}$ These are fixed-effects-only one-inflated beta regressions, on each independent variable, of the proportion of time that a provider was satisfied with their clinical practice

In the mixed-effects zero-inflated multivariable beta regression model of dissatisfaction frequency (Table $4 b$ ), the independently significant mean regressors were workload and relatedness; variance regressors that were independently significant were autonomy and risk aversion; and the significant zero-inflation regressors were workload, relatedness, meaningfulness, and intolerance of uncertainty. Working in a non-primary-care specialty had a marginally non-significant effect in the variance submodel. The inference from the mean submodel is that, on average, more fulfilled relatedness needs were associated with less frequent dissatisfaction. Higher workload, by contrast, was linked to more frequent dissatisfaction. The variance submodel implies that more fulfilled autonomy needs and greater risk aversion were associated with increased variation in the dissatisfaction frequency. The inference from the zero-inflation submodel is that greater fulfillment of relational needs, and a higher meaning in patient care increased the likelihood of being among the least frequently dissatisfied practitioners; a heavier workload and greater intolerance of uncertainty had the opposite effect.

\section{Discussion}

We sought to investigate the factors that had the most significant predictive association with the proportion of time that group-employed, rural physicians and mid-level practitioners in upstate New York were satisfied or dissatisfied with practice. Practitioners with greater workloads and/or intolerance of uncertainty were less likely to enjoy top-quintile satisfaction; higher work meaningfulness increased that likelihood. Practitioners with more gratified relational needs and work meaningfulness were more likely to be in the bottom quintile of dissatisfaction. Heavier workloads and greater intolerance of uncertainty were linked to less likelihood of being in the bottom quintile in terms of dissatisfaction frequency.

The present study highlighted the role of workload as both a motivating and hygiene factor among clinicians. Subjective perceptions of workload quantity, rather than objective amounts of workload, drive the feelings of dissatisfaction [60, 82]. More intense workloads lead to heightened job stress or role strain, which diminishes professional satisfaction [83]. Thomassen and colleagues report that increased workload is linked to depression among rural physicians [84]. Lavanchy and colleagues cite manageable on-call shifts as one of the principal predictors of professional satisfaction [43]. The degree of autonomy permitted to the individual practitioner and the level of support rendered to them by their organization could moderate the effect(s) of workload on professional satisfaction and well-being [85]. 
Table 3 Univariate beta regressions ${ }^{a}$ of the proportion of time that practitioners were dissatisfied

\begin{tabular}{|c|c|c|c|}
\hline \multirow[t]{2}{*}{ Parameter } & Mean sub-model & \multirow{2}{*}{$\begin{array}{l}\text { Variance sub-model } \\
\text { Estimate (standard error) }\end{array}$} & \multirow{2}{*}{$\begin{array}{l}\text { Zero-inflation sub-mode } \\
\text { Estimate (standard error) }\end{array}$} \\
\hline & Estimate (standard error) & & \\
\hline Male gender & $0.3163(.0653)$ & $0.7991(.1178)$ & $0.4602(.1203)$ \\
\hline Married & $0.3793(.0640)$ & $0.8491(.1149)$ & $0.7093(.1246)$ \\
\hline Age $<45$ years & $-0.1401(.0917)$ & $-30.8125(.0080)$ & $-0.6703(.0262)$ \\
\hline Organizational Tenure $<15$ years & $0.2477(954.48)$ & $1.1063(1773.45)$ & $0.2921(.1184)$ \\
\hline Works Fulltime & $0.3827(.0707)$ & $0.8891(.1230)$ & $0.3757(.1250)$ \\
\hline Works Part-time/Per Diem & $0.2852(.0897)$ & $1.0609(.1861)$ & $0.4195(.1875)$ \\
\hline Doctor & $0.0353(.0718)$ & $0.4413(.1315)$ & $0.1360(.1302)$ \\
\hline Advanced-Practice Clinician (APC) & $-0.1661(.0629)$ & $0.4915(.1134)$ & $-0.2498(.1167)$ \\
\hline Works in Primary Care & $0.3484(.0663)$ & $1.0523(.1299)$ & $0.0484(.1444)$ \\
\hline Not in Primary Care & $0.3331(.0630)$ & $0.8732(.1141)$ & $0.6652(.1172)$ \\
\hline Workload $\psi$ & $0.2335(.0726)$ & $-0.1773(.1464)$ & $-1.1792(.1637)$ \\
\hline Autonomy Needs $\psi$ & $-0.1559(.0677)$ & $0.2300(.1107)$ & $0.6356(.1437)$ \\
\hline Relatedness Needs $\psi$ & $-0.1528(.0655)$ & $0.0593(.1113)$ & $0.7209(.1429)$ \\
\hline Meaningfulness of Practice $\psi$ & $0.0214(.0626)$ & $0.1381(.0934)$ & $0.3828(.1234)$ \\
\hline Risk Aversion $\psi$ & $-0.0453(.0599)$ & $0.2256(.1026)$ & $-0.2603(.1181)$ \\
\hline Intolerance of Uncertainty $\psi$ & $-0.0482(.0659)$ & $0.2384(.1264)$ & $-0.4419(.1238)$ \\
\hline Unit Support Staff F.T.E.S $\psi$ & $0.0156(.0541)$ & $0.0916(.0999)$ & $-0.1679(.1176)$ \\
\hline Clinical Unit of $\leq 5$ Practitioners & $-1.6490(.1106)$ & $-26.1024(.2091)$ & $-1.7937(1.0024)$ \\
\hline
\end{tabular}

Note: Bolded figures indicate statistical significance at the alpha $=0.05$ significance level

$\Psi=$ This continuous variable was standardized

${ }^{\text {a }}$ These are fixed-effects-only zero-inflated beta regressions, on each independent variable, of the proportion of time that a provider was dissatisfied with their clinical practice

Practitioners with more fulfilled relatedness needs were significantly more likely to enjoy frequent satisfaction, and to report being dissatisfied only a minimal amount $(0-20 \%)$ of the time. Relatedness was both a motivator and hygiene factor. There could be a selection effect whereby practitioners that elect to serve our rural communities were more motivated by the need to feel a strong sense of community and connectedness [34, 86]. Nevertheless, supportive professional relationships assist clinicians in coping with practice stress [87], thus reducing the likelihood of job distress and burnout [88]. The social support of their peers satisfies practitioners more than employee assistance programs initiated by managers [89]. Among employed practitioners, positive peer relationships influence quality of work life more powerfully than staff support, job control, income, or time pressure [90]. The quality of work relationships has also been linked to attrition from clinical practice $[88,91]$.

In this study, the extent to which practitioners perceived their autonomy needs as gratified had a positive association with the variance in dissatisfaction with practice. Autonomy was a hygiene factor rather than a motivator. Medical professionals require an optimum level of clinical autonomy in order to exercise the fiduciary duty of providing healthcare services with the interests of the patient being their foremost consideration [92].
Practitioners need strong autonomy support not just from their practice managers or supervisors, but also from their professional peers [93]. Studies consistently find significant associations between autonomy and job satisfaction among physicians [94-96] and advancedpractice clinicians [97-99]. The escalation of regulations and mandates during the current health reform era, coupled with the wave of institutional consolidations/ amalgamations and trends towards individual practitioners choosing employment rather independent practice, has led to widespread erosion of individual autonomy [6]. In order to protect clinician well-being during systemic and institutional reform, clinicians and practice managers should collaborate to find innovative ways of sheltering professional autonomy [100]. Autonomy can be re-configured from an individualized to a group concept and exercised collectively or collaboratively $[101,102]$.

In our study, clinicians who derived greater intrinsic meaning from their practice had a significantly greater likelihood of being in the top quintile of satisfaction and/or being in the bottom quintile of dissatisfaction. Work meaningfulness was a motivator and a hygiene factor. Despite calls for enhancing meaning in clinical work as a means of improving professional wellbeing $[103,104]$, the construct of work meaningfulness has 
Table 4 Multivariable inflated beta regression models

\begin{tabular}{|c|c|c|c|c|}
\hline \multicolumn{5}{|c|}{ (a) Multivariable Mixed-Effects One-Inflated Beta Regression Model of Satisfaction with Practice ${ }^{a}$} \\
\hline Sub-Model & Parameter & Estimate (standard error) & $95 \%$ Confidence Interval of Estimate & t statistic ( $p$ value) \\
\hline \multirow[t]{5}{*}{ Mean } & Intercept ( $\left.b_{0}\right)$ & $-0.1130(.0609)$ & $-0.2344,-0.0084$ & $-1.85(.0677)$ \\
\hline & Workload $\psi$ & $-0.3400(.0602)$ & $-0.4600,-0.2200$ & $-5.65(<.0001)$ \\
\hline & Autonomy needs $\psi$ & $0.1280(.0721)$ & $-0.0158,0.2717$ & $1.77(.0802)$ \\
\hline & Relatedness needs $\psi$ & $0.1898(.0761)$ & $0.0382,0.3414$ & $2.49(.0149)$ \\
\hline & Meaningfulness $\psi$ & $0.2372(.0533)$ & $0.1309,0.3435$ & $4.45(<.0001)$ \\
\hline Variance & Intercept $\left(\mathrm{d}_{0}\right)$ & 1.9907 (.0991) & $1.7931,2.1882$ & $20.09(<.0001)$ \\
\hline \multirow[t]{5}{*}{ One-Inflation } & Intercept (one $)_{0}$ & $-1.0837(.1699)$ & $-1.4233,-0.7452$ & $-6.38(<.0001)$ \\
\hline & Workload $\psi$ & $-1.0294(.1892)$ & $-1.4065,-0.6523$ & $-5.44(<.0001)$ \\
\hline & Meaningfulness $\psi$ & $0.6373(.1750)$ & $0.2885,0.9861$ & $3.64(.0005)$ \\
\hline & Intolerance of Uncertainty $\psi$ & $-0.4058(.1600)$ & $-0.7246,-0.0870$ & $-2.54(<.0001)$ \\
\hline & Unit Support Staff F.T.E.s $\psi$ & $-0.3886(.1832)$ & $-0.7538,-0.0235$ & $-2.12(.0373)$ \\
\hline
\end{tabular}

(b) Multivariable Mixed-Effects Zero-Inflated Beta Regression Model of Dissatisfaction with Practice ${ }^{b}$

\begin{tabular}{cllll} 
Sub-Model & Parameter & Estimate (standard error) & $95 \%$ Confidence Interval of Estimate & t statistic $(p$ value) \\
Mean & Intercept $\left(b_{0}\right)$ & $-0.7590(.0266)$ & $-0.8119,-0.7061$ & $-28.59(<.0001)$ \\
& Workload $\psi$ & $0.2732(.0601)$ & $0.1534,0.3929$ & $4.55(<.0001)$ \\
Variance & Relatedness needs $\psi$ & $-0.2437(.0592)$ & $-0.3618,-0.1257$ & $-4.12(.0001)$ \\
& Intercept $\left(d_{0}\right)$ & $2.2825(.1429)$ & $1.9977,2.5673$ & $15.98(<.0001)$ \\
& Autonomy needs $\psi$ & $0.3616(.0961)$ & $0.1701,0.5531$ & $3.76(.0003)$ \\
& Risk Aversion $\psi$ & $0.2410(.0941)$ & $0.0535,0.4285$ & $2.56(.0125)$ \\
Zero-Inflation & Intercept (zero $)$ & $-1.1645(.2906)$ & $-1.7438,-0.5852$ & $-4.01(.0001)$ \\
& Not in Primary Care & $0.6665(.3464)$ & $-0.0240,1.3569$ & $1.92(.0583)$ \\
& Workload $\psi$ & $-1.1722(.1932)$ & $-1.5574,-0.7870$ & $-6.07(<.0001)$ \\
& Relatedness $\psi$ & $0.5691(.1722)$ & $0.2258,0.9124$ & $3.30(.0015)$ \\
& Meaningfulness $\psi$ & $0.6738(.1807)$ & $0.3136,1.0339$ & $3.73(.0004)$ \\
& Intolerance of Uncertainty $\psi$ & $-0.3895(.1608)$ & $-0.7101,-0.0689$ & $-2.42(.0179)$ \\
\hline
\end{tabular}

${ }^{\mathrm{a}}$ Goodness of Fit Statistics: -2 Log Likelihood $=113.3 ; \mathrm{AIC}=141.3 ; \mathrm{BIC}=173.6$

${ }^{\text {b }}$ Goodness of Fit Statistics: -2 Log Likelihood $=100.1 ; \mathrm{AIC}=130.1 ; \mathrm{BIC}=164.4$

$\Psi=$ This continuous variable was standardized

not been thoroughly investigated among medical practitioners. Theory and anecdotal evidence suggest that meaningful work is experienced as highly significant and holding positive intrinsic meaning for the practitioner [105]. In a narrative analysis of stories written by physicians about work-related experiences that they found meaningful, Horowitz and colleagues found 3 principal themes: making a connection with patients, impacting someone's life, and a fundamental change in the doctor's perspective [106]. Those who find high intrinsic meaning in their work often view their profession as a "calling" [107]. Cardador and colleagues found that physicians who saw medicine as a calling had greater commitment to their healthcare organization, since they viewed it as instrumental in helping them to achieve their deeply valued professional goals [108]. In another study, such physicians reported greater satisfaction with providing treatment for complex conditions such as smoking, alcoholism and obesity than their counterparts [109]. Among 220 certified nurse midwives, Brianna Caza found that high meaningfulness of the work was associated with reduced burnout [110]. Our study contributes to this growing empirical evidence of the underlying role of work meaningfulness in the quality of work life of medical professionals.

Practitioners that are highly intolerant of uncertainty/ ambiguity were less likely to be in the top quintile of satisfaction and bottom quintile of dissatisfaction. Ambiguity tolerance functioned both as a motivator and hygiene factor. Our finding corroborates results from a study among Swiss physicians, in which uncertainty intolerance was associated with low job satisfaction [111]. Inability to tolerate ambiguity is implicated in fomenting job distress during medical training [112]. Among doctors, uncertainty intolerance is also associated with poor stewardship of healthcare resources [113], negative 
attitudes towards dying patients [114] or the underserved [115], poor diagnostic performance [116], and not adhering to medical evidence [117]. Those practitioners who tolerate uncertainty well find cognitively ambiguous clinical scenarios intellectually stimulating [118]. Since such uncertainties are commonplace in medical practice, those who see them as opportunities to grow can build their tolerance further [119, 120], enhancing the quality of their work life. Those who are intolerant of uncertainty seek to avoid ambiguous stimuli, which further degrades their ambiguity-processing capacity $[119,120]$, and undermines their professional satisfaction.

Risk aversion was significantly associated with variance in the dissatisfaction frequency but did not manifest significance in other sub-models. For purposes of brevity and due to space constraints, only two items of the risktaking subscale were included in our survey, which may have limited the sensitivity of the measure. Risk tolerance refers to differential attention and reactions of individuals to stimuli in situations that are potentially risky. Risk-averse individuals differ from risk-takers in the way they evaluate a work setting [121], e.g. in their perceptions about the quality of work life. Risk-averse people put a high premium on procedural justice and fairness in an organization [122], which they see as restoring or maintaining predictability. Future studies should examine further the role that risk aversion plays in fomenting job stress among medical practitioners and how to avert or mitigate its effects.

Unlike the Great American Physician Survey [123], our study found no independent association between a practitioner's age or employment tenure and their dis/ satisfaction with practice. The significant associations of age and tenure with practice dis/satisfaction, in the univariate models, did not persist once we accounted for other covariates. Among the characteristics of a practice unit, only the level of support staffing manifested an independent effect. Serving on a unit with higher coverage by support staff was significantly associated with a reduced likelihood of being in the most satisfied quintile of practitioners. The level of support staffing on a unit could, however, reflect the clinical workload for which the unit is responsible. Differences in practice satisfaction by other demographic categories, such as gender, marital status, fulltime status, practice scope, and primary versus specialty/subspecialty practice, largely reflect confounding between individual demographics and the principal psychosocial factors described above.

\section{Strengths and limitations}

Since we employed a survey methodology to collect data on various psychosocial and demographic factors, selection biases could limit the external validity of our findings. Our respondents did not systematically differ from non-responders on demographics, with the exception of median organizational tenure (respondents 7.8 years versus 4.8 for non-responders; $p<0.0001$ ). The cross-sectional observation design of this study also means that we could not definitively establish the temporal evolution of dissatisfaction. The unique rural and small-town setting for the study is also a potential limit on external validity. Omitted variable bias is another potential downside, since we excluded some plausible constructs and limited the questionnaire's length in order to prevent it from getting unwieldy, which can cause poor response rates. For non-physicians who have no independent practice, satisfaction with the supervising physician and acknowledgement of the PA/NP role by rural communities are two factors, highlighted by prior studies, which we did not measure. Our findings should be cautiously interpreted as limited, context-specific evidence until they are replicated in longitudinal studies and quasi experiments across multiple, diverse contexts or settings. Linking survey data to administrative information meant that our analysis included, not just self report variables but, objective measures too. An additional strength was the sophisticated analysis strategy that was robust to clustering in the sample (clinicians nested within practice units), the skewed (non-normal) distribution of the outcomes plus their configuration as proportions. Many similar studies make questionable assumptions that outcomes are linear or normally distributed (hence the frequent recourse to ordinary least squares regression), or use controversial methods of transforming the data to try and eliminate the skew. Our conservative approach rested on as few unsupported assumptions as possible. The response rate $(65.1 \%)$ to our survey compares favorably with those reported by other studies of medical professionals, a further strength.

\section{Implications}

This study emphasizes the importance of continuous tracking of practitioner satisfaction (which is as important as patient satisfaction, a metric already being tracked regularly) by practice leaders and healthcare organization managers. The proportion of time that practitioners, were satisfied or dissatisfied had a predictive association with mutable factors such as workload, autonomy and relational needs, work meaningfulness, attitudes towards uncertainty/ambiguity and risk taking or aversion, and the support staffing. Healthcare organizations should redesign systems to enhance inter-professional, multidisciplinary teamwork as a strategy for alleviating perceptions of inequity in the division of clinical labor and fulfilling the practitioners' relational needs. Managers of health institutions should help to build supportive peer networks or professional communities that increase social capital and 
reduce loneliness/isolation, particularly among practitioners in rural settings. Practitioner groups or associations should negotiate with healthcare organizations and third party payers in order to find innovative ways of balancing professional autonomy with accountability. Leadership coaching should be given to practitioners to enhance their skills of dealing with situations with uncertain and potentially risky outcomes. Training in ambiguity tolerance skills ought to be incorporated within medical education curriculums [124]. Awareness campaigns can use social marketing strategies to "market" a professionalism built on a healthier balance between work life and personal/family life among health practitioners.

\section{Conclusion}

Group-employed, rural practitioners who report having a higher workload and being intolerant of clinical ambiguity are less likely to belong to the most frequently satisfied and least frequently dissatisfied quintiles, but finding patient-care inherently meaningful and having more of one's relational needs fulfilled increases that likelihood. Workload, relatedness, meaningfulness and ambiguity intolerance are both motivators and hygiene factors. Support staffing is a motivator, while autonomy and risk aversion are hygiene factors. Once these mutable factors are accounted for, individual practitioner demographics and most practice unit characteristics do not manifest an independent association with the frequency of dis/satisfaction with rural practice.

\section{Endnotes}

${ }^{1}$ The one-inflation submodel assessed the probability that the frequency of satisfaction reached or exceeded $80 \%$; whereas the zero-inflation submodel assessed the probability that frequency of dissatisfaction did not exceed $20 \%$.

\section{Abbreviations \\ ACOs: Accountable-Care Organizations; AIC: Akaike Information Criterion; APC: Advanced-practice clinician; BIC: Bayesian Information Criterion; Cl: Confidence interval; CNAs: Certified nurse assistants; FTEs: Full-time equivalents; GAMLSS: Generalized additive model for location, scale and shape; IRB: Institutional Review Board; LPNs: Licensed practical nurses; NC: North Carolina; NLMIXED: Non-linear mixed regression procedure; NP: Nurse practitioner; PA: Physician assistant; PCAs: Personal care assistants; PRAWS: Practitioner Resilience, Adaptability and Well-being Study; $\mathrm{Q}_{1}$ or q1: first quartile; $\mathrm{Q}_{3}$ or q3: third quartile; RNs: Registered nurses; SAS ${ }^{\mathrm{T}}$ : Statistical Analysis Software; SDT: Self-determination theory; U.S.: United States}

\section{Acknowledgements}

The authors thank the doctors and advanced-practice practitioners who generously responded to the PRAWS baseline survey. We are also thankful to our Advisory Board for their unfailing support and guidance. Reginald Knight, MD, the past President of the Bassett Medical Staff Group, and his Executive Committee, helped to publicize the survey and frequently encouraged fellow practitioners to participate. Shannon Crisman provided valuable research assistance in the earliest phases of the PRAWS project. Melinda Hasbrouck, MBA, and Moira Riley, PhD, served as research coordinators on the study team. Earlier drafts of this manuscript benefited from comments and suggestions made by August Leinhart, MD, an Emergency Medicine specialist, and Brian White, DO, a physiatrist, at Bassett Medical Center, Cooperstown, NY. We thank the editors and peer reviewers of the BMC Health Services Research journal for their insightful suggestions. We further acknowledge Laura Dixon, MLS, and Matthew Roslund, MLS, of the McKenzie Medical Library at Bassett Medical Center, for their help in securing copyright permissions and manuals for the proprietary scales that are utilized in the PRAWS project.

\section{Funding}

No extramural funding supported this study.

\section{Availability of data and materials}

The datasets generated during and/or analyzed during the current study are not publicly available due to restrictions in the IRB protocol that are intended to protect the privacy and confidentiality of participants.

\section{Authors' contributions}

Authorship of this paper is attributed on the following basis: ACW was the principal investigator on the parent project, and originated the concept for this study, led and guided the quantitative analysis, and a provided an initial working draft of the paper for other authors to review and edit. MS participated in the study design, data cleaning and analysis, and contributed substantially to re-drafting the text of the manuscript. NK participated in data entry, database management, data cleaning and internal consistency checks, and statistical analyses. JJM contributed to the study conceptualization and design, interpretation of findings, and redrafting of the manuscript. PJ helped to plan the quantitative analyses and methodological approach, supervised data handling processes, provided statistical interpretation during the analysis, verified all quantitative findings, and helped to re-edit the manuscript draft. All authors read and approved the final manuscript.

\section{Competing interests}

The authors declare that they have no competing interests.

\section{Consent for publication}

No details on individual participants are published in this manuscript. Full disclosure was made to the participants, during the informed consent process, that the study would yield publications but that these would contain only aggregate information.

\section{Ethics approval and consent to participate}

The parent study was ethically vetted and approved by the Institutional Review Board (IRB) at the hosting academic medical center as Project Number 1052. The IRB determined that the study presented only minimal risk to participants. Researchers provided each prospective respondent with an information sheet containing a detailed description of the study. After reading and absorbing the information, each individual then freely decided whether to consent or decline to participate. The study is further overseen by an advisory board comprised of representatives of the community of practitioners from whom participants were drawn.

\section{Disclaimer}

The findings that are reported in this research manuscript are solely those of its authors and do not represent the official or unofficial views of any of the institutions to which the authors are affiliated, either individually or severally.

\section{Author details}

'Bassett Healthcare Network, Research Institute, 1 Atwell Road, Cooperstown, NY 13326, USA. ${ }^{2}$ Columbia University College of Physicians and Surgeons, 630 West 168th St, New York, NY 10032, USA. ${ }^{3}$ Columbia University Mailman School of Public Health, 722 West 168th St, New York, NY 10032, USA.

Received: 10 December 2015 Accepted: 21 September 2016

Published online: 22 October 2016

\section{References}

1. Dyrbye LN, Shanafelt TD. Physician burnout: a potential threat to successful health care reform. JAMA. 2011;305(19):2009-10.

2. Arnetz BB. Psychosocial challenges facing physicians today. Soc Sci Med. 2001;52:203-13. 
3. Shanafelt TD, Sloan JA, Habermann TM. The well-being of physicians. Am J Med. 2003;114(6):513-9.

4. Xu X, Siefert KA, Jacobson PD, Lori JR, Ransom SB. The impact of malpractice burden on michigan obstetrician-gynecologists' career satisfaction. Womens Health Issues. 2008;18(4):229-37.

5. Carrier ER, Reschovsky JD, Mello MM, Mayrell RC, Katz D. Physicians' fears of malpractice lawsuits are not assuaged by tort reforms. Health Aff. 2010;29(9):1585-92.

6. Emmanuel EJ, Pearson SD. Physician autonomy and health care reform. JAMA. 2012:307(4):367-8

7. Wallace JE, Lemaire JB, Ghali WA. Physician wellness: a missing quality indicator. Lancet. 2009;374(9702):1714-21.

8. Murray A, Montgomery JE, Chang H, Rogers WH, Inui H, Safran DG. Doctor discontent: a comparison of physician satisfaction in different delivery system settings, 1986 and 1997. J Gen Intern Med. 2001;16(7):451-9.

9. Mechanic D. Physician discontent: challenges and opportunities. JAMA. 2003;290(7):941-6.

10. Landon BE, Aseltine Jr R, Shaul JA, Miller Y, Auerbach BA, Cleary PD. Evolving dissatisfaction among primary care physicians. Am J Manag Care. 2002;8(10):890-901.

11. Zuger A. Dissatisfaction with medical practice. N Engl J Med. 2004;350(1):69-75.

12. Shanafelt TD, Boone S, Tan L, Dyrbye LN, Sotile W, Satele D, West CP, Sloan J, Oreskovich MR. Burnout and satisfaction with work-life balance among U. S. physicians relative to the general U.S. population. Arch Intern Med. 2012:172(18):1377-85.

13. Center C, Davis M, Detre T, Ford DE, Hansbrough W, Hendin H, Laszlo J, Litts DA, Mann J, Mansky PA, Michels R, Miles SH, Proujansky R, Reynolds III CF, Silverman MM. Confronting depression and suicide in physicians: a consensus statement. JAMA. 2003;289(23):3161-6.

14. Gold KJ, Sen A, Schwenk TL. Details on suicide among U.S. physicians: data from the national violent death reporting system. Gen Hosp Psychiatry. 2013;35(1):45-9.

15. Clever LH. Who is sicker: patients or residents? Residents' distress and the care of patients. Ann Intern Med. 2002;136(5):391-3.

16. Haas JS, Cook EF, Puopolo AL, Burstin HR, Cleary PD, Brennan TA. Is the professional satisfaction of general internists associated with patient satisfaction? J Gen Intern Med. 2000;15(2):122-8.

17. Melville A. Job satisfaction in general practice implications for prescribing. Soc Sci Med. 1980;14A(6):495-9.

18. DeVoe J, Fryer Jr GE, Hargraves JL, Phillips RL, Green LA. Does career dissatisfaction affect the ability of family physicians to deliver high-quality patient care? J Fam Pract. 2002;51(3):223-8.

19. Shanafelt TD, Balch CM, Bechamps G, Russell T, Dyrbye LN, Satele D, Collicott P, Novotny P, Sloan J, Freischlag J. Burnout and medical errors among American surgeons. Ann Surg. 2010;251(6):995-1000.

20. Williams ES, Skinner AC. Outcomes of physician job satisfaction: a narrative review, implications, and directions for future research. Health Care Manag Rev. 2003;28:119-39.

21. Landon BE, Reschovsky J, Pham HH, Blumenthal D. Leaving medicine: the consequences of physician dissatisfaction. Med Care. 2006;44(3):234-42.

22. Buchbinder SB, Melick CF, Powe NR. Managed care and primary care physicians' overall career satisfaction. J Healthcare Finance. 2001;28(2):35-44.

23. Schloss EP, Flanagan DM, Culler CL, Wright AL. Some hidden costs of faculty turnover in clinical departments in one academic medical center. Acad Med. 2009;84(1):32-6.

24. Stovall JG, Schutte L. Investing in Retention Pays Dividends. Group Pract J. 2011;60:40-3.

25. Hart LG, Salsberg E, Phillips DM, Lishner DM. Rural health care providers in the United States. J Rural Health. 2002;18(Suppl):211-32.

26. Stevenson $A D$, Phillips $C B$, Anderson KJ. Resilience among doctors who work in challenging areas: a qualitative study. $\mathrm{Br} J$ Gen Pract. 2011;61(588):e404-10.

27. Morley CP. Supporting physicians who work in challenging contexts: a role for the academic health center. J Am Board Fam Med. 2012;25(6):756-8.

28. Nelson WA. Boundary issues in rural America. Overlapping relationships create ethical challenges for rural healthcare professionals. Healthc Exec. 2010;25(2):54, 56-57.

29. Purtilo R, Sorrell J. The ethical dilemmas of a rural physician. Hastings Cent Rep. 1986;16(4):24-8.

30. Cook AF, Hoas H, Guttmannova K. Ethical issues faced by rural physicians. S D J Med. 2002;55(6):221-4.
31. Simon RI, Williams IC. Maintaining treatment boundaries in small communities and rural areas. Psychiatr Serv. 1999;50(11):1440-6.

32. Eley D, Young L, Shrapnel M. Rural temperament and character: a new perspective on retention of rural doctors. Aust J Rural Health. 2008;16(1):12-22.

33. Henry LR, Hooker RS. Retention of physician assistants in rural health clinics. J Rural Health. 2007;23(3):207-14.

34. Hancock C, Steinbach A, Nesbitt TS, Adler SR, Auerswald CL. Why doctors choose small towns: a developmental model of rural physician recruitment and retention. Soc Sci Med. 2009;69(9):1368-76.

35. Haggerty TS, Fields SA, Selby-Nelson EM, Foley KP, Shrader CD. Physician wellness in rural America: a review. Int J Psychiatry Med. 2013;46(3):303-13.

36. Miller SM. Buying Craze: Hospital Groups Acquiring Physicians' Private Practices, in Clear and Convincing Evidence. Eagleville: The official blog of the law firm McCumber Daniels Buntz Hartig \& Puig; 2011.

37. Rosenthal E. Apprehensive, Many Doctors Shift to Jobs With Salaries, in New York Times. February 13, 2014. New York: The New York Times Company; 2014. p. A14.

38. Callan VJ, Gallois C, Mayhew MG, Grice TA, Tluchowska M, Boyce R. Restructuring the multi-professional organization: professional identity and adjustment to change in a public hospital. J Health Hum Serv Adm. 2007;29(4):448-77.

39. Charles AG, Ortiz-Pujols S, Ricketts T, Fraher E, Neuwahl S, Cairns B, Sheldon GF. The Employed Surgeon: A Changing Professional Paradigm. JAMA Surg. 2013;148(4):323-8

40. Medscape, Employed Doctors Report: Are They Better Off? http://www. medscape.com/features/slideshow/public/employed-doctors [Accessed 31 Jul 2016], Kane, L., Editor. 2014, Medscape, LLC: New York, NY.

41. Beasley JW, Karsh BT, Hagenauer ME, Marchand L, Sainfort F. Quality of work life of independent vs employed family physicians in Wisconsin: A WReN study. Ann Fam Med. 2005;3(6):500-6.

42. Thompson JA, Van de Ven AH. Commitment shift during organizational upheaval: physicians' transitions from private practitioner to employee. J Vocat Behav. 2002;60(3):382-404.

43. Lavanchy M, Connelly I, Grzybowski S, Michalos A, Berkowitz J, Thommasen H. Determinants of Rural Physicians' Life and Job Satisfaction. Soc Indic Res. 2004;69(1):93-101.

44. Filipova AA. Factors influencing the satisfaction of rural physician assistants: a cross-sectional study. J Allied Health. 2014;43(1):22-31.

45. Schiestel C. Job satisfaction among Arizona adult nurse practitioners. J Am Acad Nurse Pract. 2007;19(1):30-4.

46. Peterson LE, Phillips RL, Puffer JC, Bazemore A, Petterson S. Most family physicians work routinely with nurse practitioners, physician assistants, or certified nurse midwives. J Am Board Fam Med. 2013;26(3):244-5.

47. Locke EA. The Nature and Causes of Job Satisfaction. In: Dunnette MD, editor. Handbook of Industrial and Organizational Psychology. Chicago: Rand McNally; 1976. p. 1297-349.

48. Mueller CW, Kim SW. The Contented Female Worker: Still a Paradox? In: Hegtvedt KA, Clay-Warner J, editors. Justice: Advances in Group Processes, vol. 25. Bingley: Emerald Group Publishing Limited; 2008. p. 117-50.

49. Brief AP, Weiss HM. Organizational behavior: affect in the workplace. Annu Rev Psychol. 2002;53(1):279-307.

50. Weiss HM, Cropanzano R. Affective Events Theory: A Theoretical Discussion of the Structure, Causes and Consequences of Affective Experiences at Work. In: Staw BM, Cummings LL, editors. Research in organizational behavior: an annual series of analytical essays and critical reviews, vol. 18. Greenwich: JAI Press Inc; 1996. p. 1-74.

51. Diener E. Subjective well-being. Psychol Bull. 1984;95(3):542-75.

52. Diener E, Sandvik E, Pavot W. Happiness is the frequency, not the intensity, of positive versus negative affect. In: Strack F, Argyle M, Schwarz N, editors. Subjective well-being: an interdisciplinary perspective. New York: Pergamon; 1991. p. 119-39.

53. Herzberg F. One More Time: How Do You Motivate Employees. Harvard: Harvard Business Review; 1968. p. 53-62.

54. Pinder CC. Human Reactions to Work, Jobs and Organizations. In: Work Motivation in Organizational Behavior, 2. New York: Psychology Press; 2008. p. 267-310.

55. Deci EL, Ryan RM. The "What" and "Why" of goal pursuits: human needs and the self-determination of behavior. Psychol Inq. 2000;11:227-68.

56. Rosso BD, Dekas KH, Wrzesniewski A. On the meaning of work: a theoretical integration and review. Res Organ Behav. 2010;30:91-127. 
57. Dik BJ, Byrne ZS, Steger MF, editors. Purpose and Meaning in the Workplace. Washington, DC: American Psychological Association; 2013.

58. Pearson SD, Goldman L, Orav EJ, Guadagnoli E, Garcia TB, Johnson PA, Lee $\mathrm{TH}$. Triage decisions for emergency department patients with chest pain: do physicians' risk attitudes make the difference? J Gen Intern Med. 1995;10(10):557-64

59. Gerrity MS, DeVellis RF, Earp JA. Physicians' reactions to uncertainty in patient care. a new measure and new insights. Med Care. 1990;28(8):724-36.

60. Mainous 3rd AG, Ramsbottom-Lucier M, Rich EC. The role of clinical workload and satisfaction with workload in rural primary care physician retention. Arch Fam Med. 1994;3(9):787-92.

61. Bakker AB, Schaufeli WB, Sixma HJ, Bosveld W, Van Dierendonck D. Patient demands, lack of reciprocity, and burnout: a five-year longitudinal study among general practitioners. J Organ Behav. 2000;21(4):425-41.

62. Waddimba AC, Nieves MA, Scribani M, Krupa N, Jenkins P, May JJ. Predictors of burnout among physicians and advanced-practice clinicians in Central New York. J Hospital Administration. 2015:4(6):21-30.

63. Waddimba AC, Scribani M, Nieves MA, Krupa N, May JJ, Jenkins P. Validation of single-item screening measures for provider burnout in a rural health care network. Eval Health Prof. 2016;39(2):215-25.

64. Thorpe C, Ryan B, McLean S, Burt A, Stewart M, Brown J, Reid G, Harris S. How to obtain excellent response rates when surveying physicians. Fam Pract. 2009;26(1):65-8.

65. Dillman DA, Smyth JD, Christian LM. Internet, phone, mail, and mixed-mode surveys: the tailored design method. 4th ed. Hoboken: Wiley; 2014.

66. Fordyce MW. A review of research on the happiness measures: a sixty second index of happiness and mental health. Soc Indic Res. 1988;20(4):355-81.

67. Fields DL. Job Satisfaction. In: Taking the Measure of Work: A Guide to Validated Scales for Organizational Research and Diagnosis. Thousand Oaks: SAGE Publications, Inc; 2002. p. 11.

68. Judge TA, Boudreau JW, Bretz Jr RD. Job and Life Attitudes of Male Executives. J Appl Psychol. 1994;79(5):767-82.

69. Wanous JP, Reichers AE, Hudy MJ. Overall job satisfaction: how good are single-item measures? J Appl Psychol. 1997;82(2):247-52.

70. Brien M, Forest J, Mageau GA, Boudrias J-S, Desrumaux P, Brunet L, Morin EM. The Basic psychological needs at work scale: measurement invariance between Canada and France. Appl Psychol Health Well-Being. 2012;4(2):167-87.

71. Geller G, Bernhardt BA, Carrese J, Rushton CH, Kolodner K. What do clinicians derive from partnering with their patients? A reliable and valid measure of "Personal Meaning in Patient Care". Patient Educ Couns. 2008;72(2):293-300.

72. Jakcson DN. Jackson Personality Inventory Manual. Goshen: Research Psychologists Press; 1975.

73. Paolino P. Maximum likelihood estimation of models with beta-distributed dependent variables. Polit Anal. 2001;9(4):325-46.

74. Kieschnick R, McCullough BD. Regression analysis of variates observed on $(0,1)$ : percentages, proportions and fractions. Stat Model. 2003;3(3):193-213.

75. Ferrari S, Cribari-Neto F. Beta Regression for Modelling Rates and Proportions. J Appl Stat. 2004;31(7):799-815.

76. Smithson M, Verkuilen J. A better lemon squeezer? Maximum-likelihood regression with beta-distributed dependent variables. Psychol Methods. 2006;11(1):54-71.

77. Pereira GH, Botter DA, Sandoval MC. A regression model for special proportions. Stat Model. 2013;13(2):125-51.

78. Smithson M, Segale C. Partition priming in judgments of imprecise probabilities. J Stat Theor Pract. 2009;3(1):169-81.

79. Carroll RJ. Variances are not always nuisance parameters. Biometrics. 2003;59(2):211-20

80. Ospina R, Ferrari SL. Inflated beta distributions. Stat Pap. 2010;51(1):111-26.

81. Ospina R, Ferrari SL. A general class of zero-or-one inflated beta regression models. Comput Stat Data Analysis. 2012;56(6):1609-23.

82. Shirom A, Nirel N, Vinokur AD. Work hours and caseload as predictors of physician burnout: the mediating effects by perceived workload and by autonomy. Appl Psychol. 2010;59(4):539-65.

83. Williams ES, Rondeau KV, Xiao Q, Francescutti LH. Heavy physician workloads: impact on physician attitudes and outcomes. Health Serv Manag Res. 2007;20(4):261-9.

84. Thommasen HV, Lavanchy M, Connelly I, Berkowitz J, Grzybowski S. Mental health, job satisfaction, and intention to relocate. Opinions of physicians in Rural British Columbia. Can Fam Physician. 2001;47:737-44.
85. Ilies R, Dimotakis N, De Pater IE. Psychological and physiological reactions to high workloads: implications for well-being. Pers Psychol. 2010;63(2):407-36

86. Cameron PJ, Este DC, Worthington CA. Professional, personal and community: 3 domains of physician retention in rural communities. Can J Rural Med. 2012;17(2):47-55.

87. Myers MF. The well-being of physician relationships. West J Med. 2001;174(1):30-3.

88. Hoff T, Whitcomb WF, Nelson JR. Thriving and surviving in a new medical career: the case of hospitalist physicians. J Health Soc Behav. 2002;43(1):72-91.

89. Hu YY, Fix ML, Hevelone ND, Lipsitz SR, Greenberg CC, Weissman JS, Shapiro J. Physicians' needs in coping with emotional stressors: the case for peer support. Arch Surg. 2012;147(3):212-7.

90. Karsh B-T, Beasley JW, Brown RL. Employed family physician satisfaction and commitment to their practice, work group, and health care organization. Health Serv Res. 2010;45(2):457-75.

91. Masselink LE, Lee SY, Konrad TR. Workplace relational factors and physicians' intention to withdraw from practice. Health Care Manag Rev. 2008:33(2):178-87.

92. Hoogland J, Jochemsen $\mathrm{H}$. Professional autonomy and the normative structure of medical practice. Theor Med Bioeth. 2000;21(5):457-75.

93. Moreau E, Mageau G. The importance of perceived autonomy support for the psychological health and work satisfaction of health professionals: not only supervisors count, colleagues too! Motiv Emot. 2012;36(3):268-86.

94. Stoddard JJ, Hargraves JL, Reed M, Vratil A. Managed care, professional autonomy, and income: effects on physician career satisfaction. J Gen Intern Med. 2001;16:675-84.

95. Katerndahl D, Parchman M, Wood R. Perceived complexity of care, perceived autonomy, and career satisfaction among primary care physicians. J Am Board Fam Med. 2009;22(1):24-33.

96. Waddimba AC, Burgess Jr JF, Young GJ, Beckman HB, Meterko M. Motivators and hygiene factors among physicians responding to explicit incentives to improve the value of care. Qual Manag Health Care. 2013;22(4):276-92.

97. Muus KJ, Geller JM, Williams JD, Ludtke RL, Knowlton DD, Hart LG. Job satisfaction among rural physician assistants. J Rural Health. 1998;14(2):100-8.

98. Lelli VR, Hickman Jr RL, Savrin CL, Peterson RA. Retail clinics versus traditional primary care: employee satisfaction guaranteed? J Am Assoc Nurse Practitioners. 2015;27(9):514-20.

99. Athey EK, Leslie MS, Briggs LA, Park J, Falk NL, Pericak A, El-Banna MM, Greene J. How important are autonomy and work setting to nurse practitioners' job satisfaction? J Am Assoc Nurse Practitioners. 2016;28(6):320-6

100. Timmermans $\mathrm{S}, \mathrm{Oh} \mathrm{H}$. The continued social transformation of the medical profession. J Health Soc Behav. 2010;51(1 Suppl):S94-106.

101. Armstrong D. Clinical autonomy, individual and collective: the problem of changing doctors' behaviour. Soc Sci Med. 2002;55(10):1771-7.

102. Rubin MA. The Collaborative autonomy model of medical decision-making. Neurocrit Care. 2014;20(2):311-8.

103. Remen RN. Recapturing the Soul of Medicine: Physicians Need to Reclaim Meaning in their Working Lives. West J Med. 2001;174(1):4-5.

104. Shanafelt TD. Enhancing meaning in work: a prescription for preventing physician burnout and promoting patient-centered care. JAMA. 2009:302(12):1338-40.

105. Shanafelt TD. Finding meaning, balance and personal satisfaction in the practice of oncology. J Support Oncol. 2005:3:157-164.

106. Horowitz CR, Suchman AL, Branch WT, Frankel RM. What do doctors find meaningful about their work? Ann Intern Med. 2003;138(9):772-5.

107. Dik BJ, Duffy RD. Calling and vocation at work: definitions and prospects for research and practice. Couns Psychol. 2009;37(3):424-50.

108. Cardador MT, Dane E, Pratt MG. Linking calling orientations to organizational attachment via organizational instrumentality. J Vocat Behav. 2011;79(2):367-78

109. Rasinski KA, Lawrence RE, Yoon JD, Curlin FA. A sense of calling and primary care physicians' satisfaction in treating smoking, alcoholism, and obesity. Arch Intern Med. 2012;172(18):1423-4.

110. Caza BB. Experience of adversity at work: toward an identity-based theory of resilience. Unpublished doctoral dissertation in Psychology. Ann Arbor: University of Michigan, ProQuest Information and Learning Company; 2007.

111. Bovier PA, Perneger TV. Stress from Uncertainty from graduation to retirement - a population-based study of Swiss physicians. J Gen Intern Med. 2007;22(5):632-8. 
112. Benbassat J, Baumal R, Chan S, Nirel N. Sources of distress during medical training and clinical practice: suggestions for reducing their impact. Med Teach. 2011;33(6):486-90.

113. Allison JJ, Kiefe Cl, Cook EF, Gerrity MS, Orav EJ, Centor R. The association of physician attitudes about uncertainty and risk taking with resource use in a medicare HMO. Med Decis Making. 1998;18(3):320-9.

114. Kvale J, Berg L, Groff JY, Lange G. Factors associated with residents' attitudes toward dying patients. Fam Med. 1999;31(10):691-6.

115. Wayne S, Dellmore D, Serna L, Jerabek R, Timm C, Kalishman S. The Association between intolerance of ambiguity and decline in medical students' attitudes toward the underserved. Acad Med. 2011;86(7):877-82.

116. Carney PA, Yi JP, Abraham LA, Miglioretti DL, Aiello EJ, Gerrity MS, Reisch L, Berns EA, Sickles EA, Elmore JG. Reactions to uncertainty and the accuracy of diagnostic mammography. J Gen Intern Med. 2007;22(2):234-41.

117. Ghosh AK. On the challenges of using evidence-based information: the role of clinical uncertainty. J Lab Clin Med. 2004;144(2):60-4.

118. Herman JL, Stevens MJ, Bird A, Mendenhall M, Oddou G. The Tolerance for ambiguity scale: towards a more refined measure for international management research. Int J Intercultural Relat. 2010;34(1):58-65.

119. Geller G. Tolerance for ambiguity: an ethics-based criterion for medical student selection. Acad Med. 2013;88(5):581-4.

120. Hancock J, Roberts M, Monrouxe L, Mattick K. Medical student and junior doctors' tolerance of ambiguity: development of a new scale. Adv Health Sci Educ Theory Pract. 2015;20(1):113-30.

121. Lind EA, Van den Bos K. When fairness works: toward a general theory of uncertainty management. Res Organ Behav. 2002;24:181-223.

122. Thau S, Aquino K, Wittek R. An extension of uncertainty management theory to the self: the relationship between justice, social comparison orientation, and antisocial work behaviors. J Appl Psychol. 2007;92(1):250-8.

123. Physicians Practice. The Great American Physician Survey 2013. Norwalk: UBM Medica, LLC; 2013. http://www.physicianspractice.com/great-americanphysician-survey/2013-great-american-physician-survey-results. Accessed 31 Jul 2016.

124. Luther VP, Crandall SJ. Ambiguity and uncertainty: neglected elements of medical education curricula? Acad Med. 2011;86(7):799-800.

\section{Submit your next manuscript to BioMed Central and we will help you at every step:}

- We accept pre-submission inquiries

- Our selector tool helps you to find the most relevant journal

- We provide round the clock customer support

- Convenient online submission

- Thorough peer review

- Inclusion in PubMed and all major indexing services

- Maximum visibility for your research

Submit your manuscript at www.biomedcentral.com/submit
Biomed Central 